ARTICLE

https://doi.org/10.1038/s41467-019-11805-6

OPEN

\title{
A rapid access to aliphatic sulfonyl fluorides
}

\author{
Ruting $\mathrm{Xu}^{1}$, Tianxiao $\mathrm{Xu}^{1}$, Mingcheng Yang${ }^{1}$, Tianpeng Cao ${ }^{1} \&$ Saihu Liao ${ }^{1}{ }^{1}$
}

The past few years have witnessed a fast-growing research interest on the study of sulfonyl fluorides as reactive probes in chemical biology and molecular pharmacology, which raises an urgent need for the development of effective synthetic methods to expand the toolkit. Herein, we present the invention of a facile and general approach for the synthesis of aliphatic sulfonyl fluorides via visible-light-mediated decarboxylative fluorosulfonylethylation. The method is based on abundant carboxylic acid feed stock, applicable to various alkyl carboxylic acids including primary, secondary, and tertiary acids, and is also suitable for the modification of natural products like amino acids, peptides, as well as drugs, forging a rapid, metal-free approach to build sulfonyl fluoride compound libraries of considerable structural diversity. Further diversification of the $\mathrm{SO}_{2} \mathrm{~F}$-containing products is also demonstrated, which allows for access to a range of pharmaceutically important motifs such as sultam, sulfonate, and sulfonamide.

\footnotetext{
${ }^{1}$ Key Laboratory for Molecule Synthesis and Function Discovery (Fujian Province University), College of Chemistry, Fuzhou University, Fuzhou 350116, China. Correspondence and requests for materials should be addressed to S.L. (email: shliao@fzu.edu.cn)
} 
apid assembly of compound libraries with high efficiency and diversity is critical to drug discovery. By virtue of the combination of strong thermodynamic driving forces and well-controlled reaction pathways, click reactions afford bond construction in an operationally simple, modular, efficient, and reliable manner. Since the introduction of the conceptual framework by Sharpless and co-workers, click chemistry has gained a great impact on many areas in the last two decades, not only organic synthesis but also biology, medicine, and materials science $^{1}$. Among various reactions identified for click chemistry, Sulfur(VI) Fluoride Exchange (SuFEx) represents the latest and also one of the most powerful click reactions ${ }^{2-5}$. Next to the recent significant progress in synthetic methodology development and polymer preparation ${ }^{6-11}$, another intriguing application of SuFEx chemistry could be the use of sulfonyl fluorides in chemical biology and molecular pharmacology as a privileged type of warheads ${ }^{12-21}$. The unique properties observed with sulfonyl fluorides could be ascribed to (i) the right balance of inherent electrophilic reactivity of $\mathrm{S}^{\mathrm{VI}}-\mathrm{F}$ and stability under physiological aqueous conditions, and (ii) the proton $\left(\mathrm{H}^{+}\right)$-mediated reactivityswitch-on mechanism that makes its reactivity sensitive to the microenvironment of the binding site, and thus allows a sitespecific targeting under various chemical and biological contexts ${ }^{2,12-14}$. The successful identification of their highly selective inhibition activity has boosted a fast-growing research interest in recent years to develop enzyme inhibitors or chemical probes based on sulfonyl fluorides ${ }^{12-26}$. However, the development in this area is significantly hampered by the limited availability of sulfonyl fluorides ${ }^{12-14}$. The potential observed with aliphatic sulfonyl fluorides, in particular the peptide-type inhibitors $^{12,22-26}$ (Fig. 1a), has drawn our attention from a synthetic point of view. Typically, aliphatic sulfonyl fluorides are prepared via fluoride-chloride exchange with the corresponding sulfonyl chlorides, which can be prepared from thiols, halides, or sultones (Fig. 1b). However, these methods have very limited sources of starting compounds ${ }^{2}$. Accordingly, a general and facile synthetic route to expand the toolkit of sulfonyl fluorides on both dimensions of synthetic efficiency and structural diversity is in high demand ${ }^{12-14}$.

Carboxylic acid is ubiquitous in nature, and widely present in natural products, medicines, and materials. The merits such as stability, low toxicity, and commercial availability make carboxylic acids as an ideal type of building blocks in organic synthesis ${ }^{27}$. We conceived that the combination of carboxylic acid as a radical source with an appropriate $\mathrm{SO}_{2} \mathrm{~F}$-containing radical acceptor would forge a general approach to various sulfonyl fluorides (Fig. 1c). With this aim in mind, we found carboxylic acids are known to readily undergo decarboxylation to release

\section{a Selected examples of aliphatic $\mathrm{RSO}_{2} \mathrm{~F}$ inhibitors}<smiles>O=[SH](F)(F)F</smiles>

AM3506 Inhibitor of FAAH<smiles>CCCCCCC(=O)O</smiles>

AM-374 Inhibitor of PPT 1<smiles>CC(C)=CCCC(C)=CCCC(C)=CCSCCOS(=O)(=O)O</smiles>

Lipoprotein lipase inhibitor<smiles>O=C([C@@H]1C[C@@H](F)CN1C(=O)c1cc(F)c(OCc2ccccc2)c(F)c1)N1CCC[C@H]1CO</smiles>

Prolyl oligopeptidase inhibitor<smiles>N[C@@H](CCC(=O)NC(CSCC[Se]F)C(=O)NCC(=O)O)C(=O)O</smiles>

G-site inhibitor for GSTP1-1

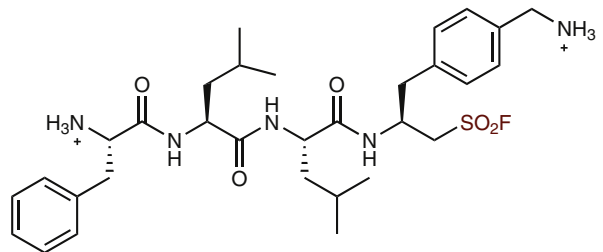

Trypsin site inhibitors for proteasome<smiles>CC(C)CC(CC(C)C)NC(=O)[C@H](CC(C)C)NC(=O)[C@H](CC(C)C)NC(=O)[C@H](CC(C)C)NC(=O)[O-]</smiles>

Proteasome inhibitor (IC50 $7 \mathrm{nM})$

\section{b Conventional routes to aliphatic sulfonyl fluorides}

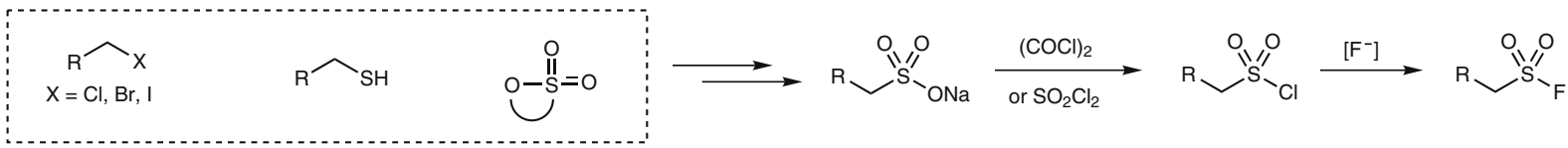

Limited starting sources for sulfonyl florides

C Synthesis of aliphatic sulfonyl fluorides from carboxylic acids via decarboxylation (this work)

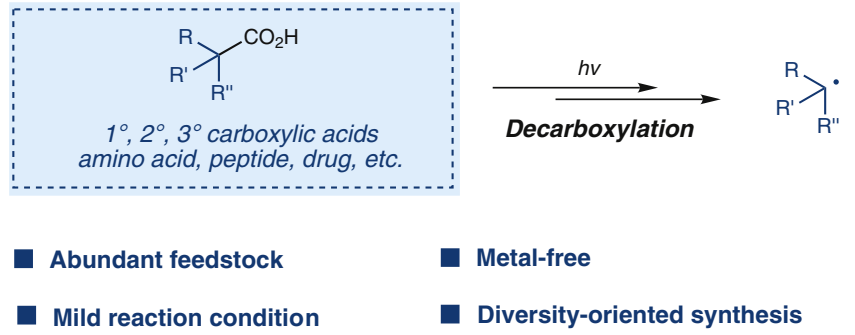

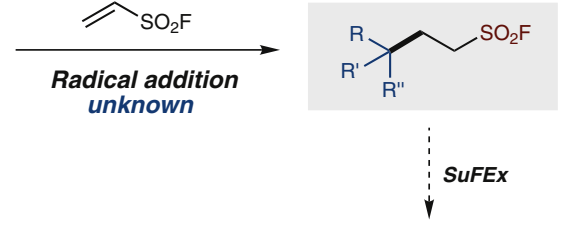

Sultams, sulfonates, sulfonamides diversification

Fig. 1 Aliphatic $\mathrm{RSO}_{2} \mathrm{~F}$ inhibitors and the synthetic strategies. a Selected examples of aliphatic sulfonyl fluoride inhibitors. $\mathbf{b}$ Conventional synthetic routes to aliphatic sulfonyl fluorides. c Synthesis of aliphatic sulfonyl fluorides from carboxylic acids via visible-light-mediated decarboxylation (this work) 
Table 1 Reaction optimization (Reaction conditions: $0.05 \mathrm{mmol}$ scale, VSF (2 eq), photocatalyst (5 mol\%), in MeCN (0.5 mL) at room temperature, under the irradiation of $18 \mathrm{~W} \times 2$ blue LED bulbs. Left entries: with DIPEA (2 eq) as the reductant. Right entries: with Eosin $\mathrm{Y}-\mathrm{Na}_{2}(5 \mathrm{~mol} \%)$ as the catalyst)
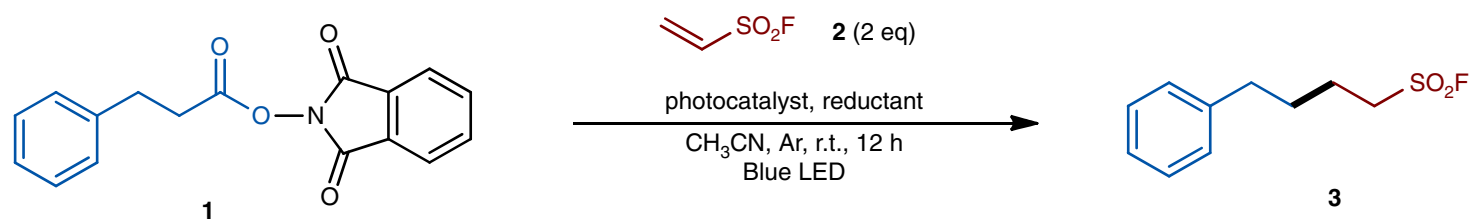

\begin{tabular}{|c|c|c|c|c|c|}
\hline Entry & Photocatalyst & Yielda $^{\mathbf{a}}$ & Entry & Reductant & Yielda $^{\mathrm{a}}$ \\
\hline 1 & $\operatorname{Ir}(\mathrm{ppy})_{3}$ & $29 \%$ & 10 & TEA & $<2 \%$ \\
\hline 2 & $\begin{array}{l}{\left[\mathrm{Ru}(\mathrm{bpy})_{3}\right]} \\
\mathrm{Cl}_{2} \cdot 6 \mathrm{H}_{2} \mathrm{O}\end{array}$ & $24 \%$ & 11 & DMA & N.P. \\
\hline 3 & Eosin $Y$ & $35 \%$ & 12 & TMEDA & $<2 \%$ \\
\hline 4 & Fluorescein & $26 \%$ & 13 & PMDETA & N.P. \\
\hline 5 & Rhodamine B & $17 \%$ & 14 & $\mathrm{HE}$ & $89 \%$ \\
\hline 6 & Rhodamine $6 \mathrm{G}$ & $26 \%$ & 15 & $\begin{array}{l}\text { HE/ } \\
\text { DIPEA 2:1 }\end{array}$ & $73 \%$ \\
\hline 7 & Isatin & $32 \%$ & 16 & $\mathrm{HE} / \mathrm{TEA}$ 2:1 & $29 \%$ \\
\hline $8^{b}$ & Eosin $Y$ & $38 \%$ & $17 c$ & $\mathrm{HE}$ & $69 \%$ \\
\hline 9 & Eosin $\mathrm{Y}-\mathrm{Na}_{2}$ & $37 \%$ & $18^{d}$ & $\mathrm{HE}$ & N.P. \\
\hline
\end{tabular}

alkyl radicals after activated in the form of $N$-hydroxyphthalimide (NHPI) esters ${ }^{28-30}$ via photocatalysis ${ }^{31-43}$ or low-valent transition metal catalysis ${ }^{44-48}$. While vinyl sulfonyl fluoride (VSF), a readily available $\mathrm{SO}_{2} \mathrm{~F}$-containing reagent ${ }^{49-54}$, could potentially be employed as the radical acceptor, though its utilization and compatibility in the radical reactions is unknown. Herein, we report our effort on this approach and the invention of a facile and general radical method for the synthesis of aliphatic sulfonyl fluorides based on naturally abundant carboxylic acid feed stock. This visible-light-mediated transformation features its high efficiency and a broad reaction scope. The wide availability of carboxylic acids, including amino acids, peptides, and many pharmaceuticals, allows for a fast construction of aliphatic sulfonyl fluoride libraries of considerable structural diversity. Further diversification of the $\mathrm{SO}_{2} \mathrm{~F}$-containing products is also demonstrated in the derivatization to pharmaceutically important motifs such as sultams, sulfonates, and sulfonamides.

\section{Results}

Reaction optimization. We commenced our study by using dihydrocinnamic acid-derived redox active ester (1) as the model substrate and diisopropylethylamine (DIPEA) as a reductant for photocatalyst screening. As shown in Table 1, with the commonly used transition metal photocatalysts, $f a c$ - $\operatorname{Ir}(\mathrm{ppy})_{3}$ gave the desired product in $29 \%$ yield (entry 1), while lower yield (24\%) was obtained with $\left[\mathrm{Ru}(\text { bpy })_{3}\right] \mathrm{Cl}_{2} \cdot 6 \mathrm{H}_{2} \mathrm{O}$ (entry 2). To our delight, eosin Y, a cheap and metal-free organic dye could furnish a slightly better yield (35\%, entry 3 ). Importantly, this metal-free system could avoid the transition metal contaminant which may bring about detrimental effect in biological and related applications ${ }^{55}$. Encouraged by this result, more organic dyes were screened (entries 4-7), such as fluorescein, rhodamine B, rhodamine $6 \mathrm{G}$, riboflavin and isatin, but none of them could give a better yield. Further increasing the VSF loading to five equivalents and the catalyst loading to $10 \mathrm{~mol} \%$ could slightly improve the yield from 35 to $38 \%$, but the improvement was quite limited (entry 8 vs. entry 3). Nevertheless, the disodium salt of eosin Y was identified slightly more efficient than eosin $\mathrm{Y}$, giving $37 \%$ yield with two equivalents of VSF only and a lower catalyst loading ( $5 \mathrm{~mol} \%$, entry 9 ).

Vinyl sulfonyl fluoride (VSF) is known about six orders of magnitude more reactive than vinyl phenyl sulfone as a Michael acceptor ${ }^{51}$; however, under this photoredox catalytic reaction condition, the yield (37\%) was even lower than that of vinyl phenyl sulfone $(45 \%)$, showing no correlation to the acceptor activity in this reaction. To our surprise, following the reaction by ${ }^{19} \mathrm{~F}$ NMR unveiled a range of mass peaks between 50 to $60 \mathrm{ppm}$, which suggested severe side reactions happened, probably due to the high reactivity of VSF and its poor compatibility with the photoredox conditions. Further reaction optimization (reductant amines, solvent, light source, etc.; see Supplementary Table 1-3) was thus performed. Surprisingly, when DIPEA was replaced with triethylamine (TEA), almost no product formed (entry 10). This dramatic effect of amine reductant was unexpected, which urged us to follow the reaction by NMR analysis and also carry out several control experiments (see Supplementary Discussion). In both cases of DIPEA and TEA, the redox active ester 1 were completely consumed after $12 \mathrm{~h}$, and almost no VSF left, so the low yields did not result from low conversion. Notably, for control reactions without redox active ester 1 , the ${ }^{19} \mathrm{~F}$ NMR also showed the disappearance of the peak of VSF, indicating that VSF may be unstable and prone to polymerize ${ }^{56}$ in the presence of DIPEA or TEA under the photoredox conditions. Therefore, more amines were tested, and finally, Hantzsch ester (HE, diethyl 1,4-dihydro-2,6-dimethyl-3,5-pyridinedicarboxylate) was found to be uniquely beneficial to the reaction, able to shut down the undesired reaction pathways and afford 3 in a decent yield of $89 \%$ (entry 14), probably by a fast hydrogen atom transfer process to the radical adduct (for mechanistic study, isotope-labeling experiments and a proposed mechanism, please see Supplementary Discussion and Supplementary Figs. 3-5). NMR experiments showed that VSF was much more stable in the presence of HE, 


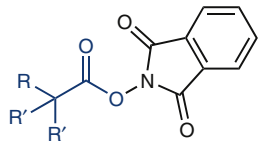

From $1^{\circ}, 2^{\circ}$ and $3^{\circ}$ acids

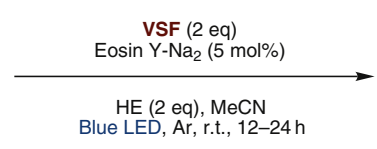

HE $(2$ eq), MeCN
Blue LED, Ar, r.t., $12-24$ h

$$
\mathrm{R}_{\mathrm{R}^{\prime \prime}}^{\mathrm{R}} \mathrm{SO}_{2} \mathrm{~F}
$$

Alkyl sulfonyl fluorides<smiles>N#Cc1ccccc1-c1c2cc(Br)c(=O)c(Br)c-2oc2c(Br)c(O[N+](=O)[O-])c(Br)cc12</smiles>

Natural products and drugs<smiles>CC(CCO[R6](=O)OCc1ccccc1)NC(CCS(=O)(=O)O)C(C)C</smiles>

31: $80 \%$<smiles>O=C(c1ccccc1)N1CCCC1CCS(=O)(=O)O</smiles>

32: $87 \%$

30: $84 \%$<smiles>O=C(NC(CCOC(=O)c1ccccc1)CCc1ccccc1)Oc1ccccc1</smiles><smiles>O=C(O)c1ccccc1NC(CCC[Se]O)C(=O)OCc1ccccc1</smiles>

Boc

33: $33 \%$

34: $65 \%$

35: $58 \%$<smiles>O=C(NC(CCCCC(=O)c1ccccc1)C(=O)OCc1ccccc1)OCc1ccccc1</smiles>

36: $64 \%$<smiles>O=C(O)CCC(NC(=O)c1ccccc1)c1ccccc1</smiles>

37: $40 \%$
12:98\%

\section{Secondary acids}<smiles>O=S(=O)(O)CCC1CCC1</smiles><smiles>O=[Sb](F)(F)CC[C]1CCCC1</smiles>

15: $74 \%$

16: $75 \%$

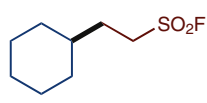

17: $98 \%$<smiles>O=S(=O)(F)CCC1CCC(F)(F)CC1</smiles>

18: $75 \%$<smiles>O=S(=O)(F)CC[C]1CC=CCC1</smiles>

19: $46 \%$

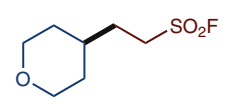

20: $85 \%$<smiles>CC(C)(C)OC(=O)N1CCC(CCS(=O)(=O)F)CC1</smiles>

21: $98 \%$<smiles>O=C1CCC(CC[Se]F)CC1</smiles>

22: $50 \%$

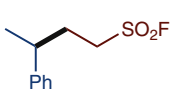

23: $60 \%$

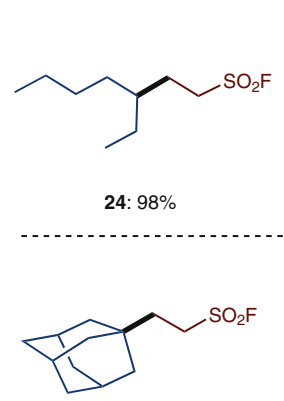

27: $81 \%$<smiles>CCCCCCCCCCCCCCCCCC(C)(C)Oc1ccc(Cl)cc1</smiles>

25: $51 \%$<smiles>CC1(CC[SH](=O)(F)F)CCCCC1</smiles>

28: $85 \%$

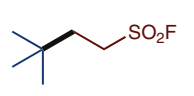

26: $60 \%$

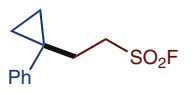

29: $72 \%$

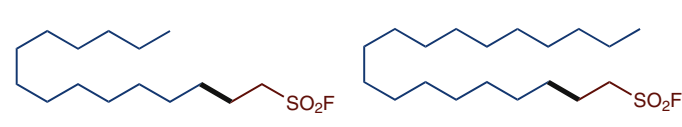

38: $75 \%$

From myristic acid

From stearic acid<smiles>CCCCCCCCCCCC[Se](F)(F)Oc1ccc(-c2ccccc2)cc1</smiles>

40: $78 \%$

From oleic acid

41: $52 \%$

From Fenbufen<smiles>Cc1ccc(C)c(OCCCC(C)(C)CCS(=O)(=O)O)c1</smiles>

42: $82 \%$

From Gemfibrozil<smiles>COc1ccc2c(c1)c(CCCS(=O)(=O)F)c(C)n2C(=O)c1ccc(Cl)cc1</smiles>

44: $85 \%$

From indometacin<smiles>CC(C)C1=CC2=CC[C@H]3C(C)(CCS(=O)(=O)F)CCC[C@]3(C)[C@H]2CC1</smiles>

43: $50 \%$

From abietic acid<smiles>C[C@H](CCCC[SH](F)(F)F)[C@H]1CC[C@H]2[C@@H]3C(=O)C[C@H]4CC(=O)CC[C@]4(C)[C@H]3CC(=O)[C@@]21C</smiles>

45: $96 \%$

From dehydrocholic acid

Fig. 2 Substrate scope. Reactions were performed on a $0.2 \mathrm{mmol}$ scale, and all yields represent isolated yields. Substrates for $\mathbf{3 3}, \mathbf{3 4}$ and $\mathbf{3 7}$ are unnaturally occurring amino acids

and even till the end of the reaction, more than $90 \%$ of the excessive one equivalent of VSF remained intact. Moreover, mixing VSF and HE without $\mathbf{1}$ under the same irradiation conditions for $12 \mathrm{~h}$ showed no detectable loss of VSF, in sharp contrast to the cases of DIPEA and TEA (for comparison, see Supplementary Figs. 1 and 2). The addition of DIPEA or TEA was even detrimental to the reaction, leading to a dramatic drop in yield (entries 15 and 16); further confirming this catalytic system 
(Eosin $\mathrm{Y}-\mathrm{Na}_{2} / \mathrm{HE}$ ) is superior to the known Eosin Y/DIPEA combination to ensure a high reaction yield. It is worth mentioning that the product could be obtained in $69 \%$ yield with one equivalent of VSF only (entry 17), while without light no reaction was observed (entry 18).

Substrate scope. With the catalytic synthetic method (Eosin Y$\mathrm{Na}_{2} / \mathrm{HE}$ ) successfully established, we next examined the reaction scope with a variety of primary, secondary and tertiary acids (Fig. 2). In cases of primary acids, bromide (5 and 13) and chloride substituents (12) were well tolerated under the present photoredox conditions and excellent yields can be achieved. Acids containing a heteroarene group like pyridine (6) or thiophene (7) are suitable substrates, though lower yield was obtained in the latter case. Acid with an alkyne moiety could deliver the desired product (14) in a moderate yield. Secondary acids with different ring sizes, all reacted well and high yields were obtained (15-22). Acyclic ones were also transformed readily (23 and 24). Tertiary acids such as alpha-oxo-acid and simple pivalic acid delivered the products $\mathbf{2 5}$ and $\mathbf{2 6}$ in good yields, respectively. Reactions could also proceed well on the six- and three-membered ring site (28 and 29). To further examine the reaction scope, a number of naturally occurring carboxylic acids and several drugs were tested. High yields were in general achieved. The decarboxylative fluorosulfonylethylation of amino acids (30-34) allows the introduction of an $\mathrm{SO}_{2} \mathrm{~F}$ group at the C-terminus of an amino acid chain, while the side-chain carboxylic acid group of aspartic

a Scale-up, one-pot reaction

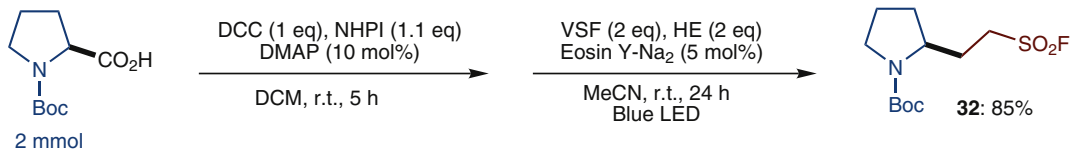

b Modification of peptide

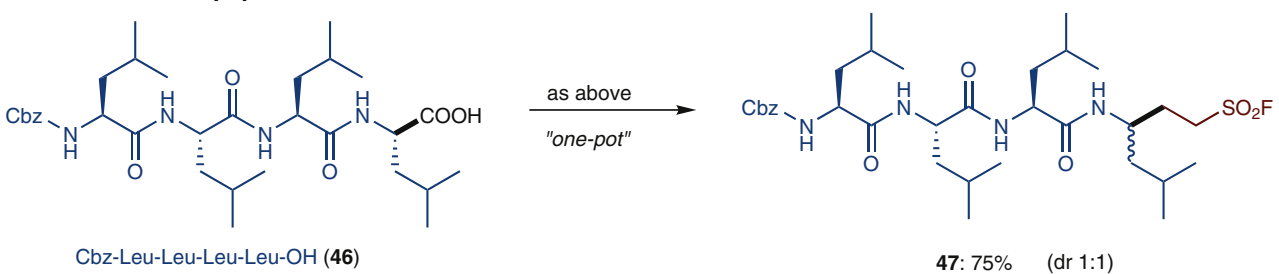

C Diversification based on SuFEx chemistry

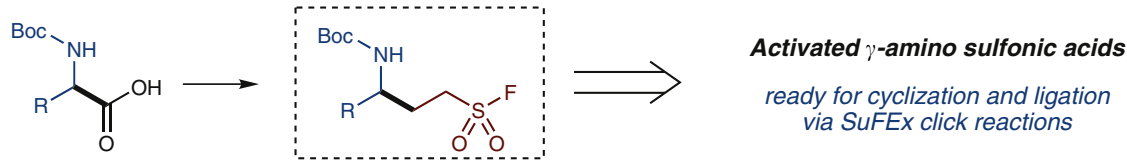

$\alpha$-amino acids

$\gamma$-amino sulfonyl fluorides

In-situ cyclization

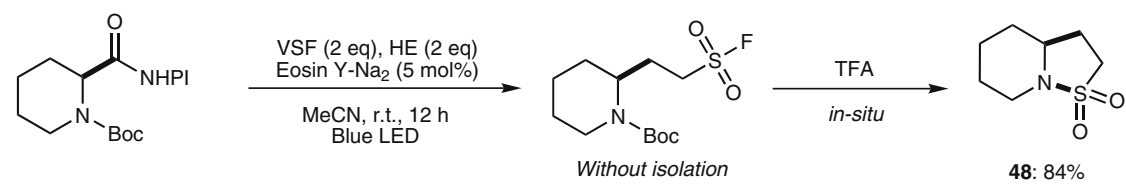

Cyclization and ligation via SuFEx chemistry

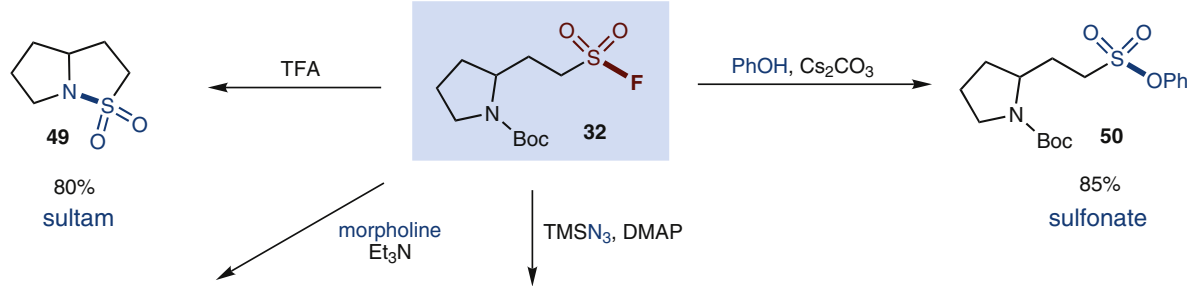

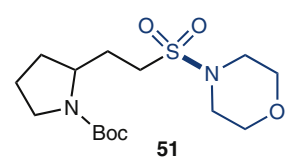

$98 \%$

sulfonamide

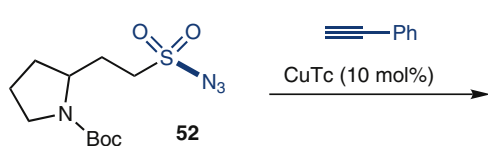

$82 \%$

sulfonyl azide

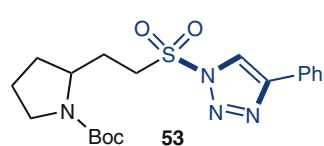

$85 \%$

sulfonyl triazole

Fig. 3 Reaction practicability and diversification of products. a Scale-up, one-pot reaction. b Modification of peptide. c Diversification of products through SuFEx chemistry 
acid and glutamic acid could also be utilized ( 35 and $\mathbf{3 6}$ ). The low isolated yield of product $\mathbf{3 3}$ is due to the difficult separation from the pyridine-byproduct of Hantzsch ester by chromatography, as the ${ }^{19} \mathrm{~F}$ NMR yield is over $90 \%$. Furthermore, the carboxylic groups of drugs such as Fenbufen, Gemfibrozil, and Indometacin could be modified readily in good to high yields to introduce the sulfonyl fluoride function through this decarboxylative approach (41-42 and 44). As outlined in Fig. 2, under the current photoredox catalytic system, primary, secondary, and tertiary carbon radicals can all be readily generated from the corresponding redox active esters and trapped by VSF in high efficiency, allowing for a fast construction of aliphatic sulfonyl fluoride libraries of considerable structural diversity. And noteworthy, primary (9), secondary (23 and 37), and tertiary (29) benzylic radicals are also well accommodated.

Product diversification. Regarding reaction practicality, the free acid can be directly used for this reaction by forming the redox active ester in situ, as exemplified in a scaled-up reaction with $\mathrm{N}$ Boc-protected L-proline (Fig. 3a). The in situ procedure proved to be equally efficient and afforded the desired product 32 in $85 \%$ isolated yield. This convenient, one-pot procedure was later employed to modify the $C$-end of a tetrapeptide (46) (Fig. 3b). The $\mathrm{SO}_{2} \mathrm{~F}$-containing product, peptide 47 is a homolog of PW28 (Fig. 1a) which exhibited high inhibition activity to proteasome $\left(\mathrm{IC}_{50} 7 \mathrm{~nm}\right)^{22,23}$. In addition, we tested the stability of the obtained product 3, 32 and tetrapeptide 47 in physiological buffers (PBS, pH 7.2), which unveiled that the three sulfonyl fluorides are quite stable under this aqueous conditions, without detectable loss or decomposition after $24 \mathrm{~h}$ by ${ }^{19} \mathrm{~F}$ NMR analysis (see Supplementary Note 1 and Supplementary Figs. 6-8). Moreover, the $\gamma$-amino sulfonyl fluoride products such as 30-34 derived from the $\alpha$-amino acids are new compounds and to some extent can be regarded as a type of activated $\gamma$-amino sulfonic acids, which would be expected to undergo cyclization or ligation to other molecules to construct pharmaceutically important motifs such as sultam, sulfonate, sulfonamide etc. ${ }^{57-61}$.

As demonstrated in Fig. 3c, bicyclic sultams 48 and 49 could be obtained in high yields via a deprotection-intramolecular cyclization sequence, which represents a facile synthetic route to sultams ${ }^{58}$. On the other hand, proline-derived sulfonyl fluoride 32 could be further diversified through SuFEx click reactions with phenol, morpholine, and $\mathrm{TMSN}_{3}$, delivering the corresponding sulfonate 50, sulfonamide 51, and sulfonyl azide 52, respectively, in high yields. Notably, the introduction of an azide group (52) allows for a further ligation to alkynes through azide-alkyne click reactions, as exemplified by the synthesis of triazole compound $\mathbf{5 3}$.

\section{Discussion}

In conclusion, a facile catalytic system has been successfully developed for the synthesis of aliphatic sulfonyl fluorides based on abundant carboxylic acid feed stock. A variety of alkyl carboxylic acids including primary, secondary, and tertiary ones, as well as amino acids, peptides, and several drugs can be readily transformed into the corresponding alkyl sulfonyl fluorides with high reaction efficiency and structural diversity. Further diversification of the sulfonyl fluoride products has been also demonstrated through the intramolecular cyclizations and SuFEx reactions. The current method provides a general and rapid approach for the synthesis of aliphatic sulfonyl fluorides and derivatives, which expands the chemical biology toolkit and could benefit the related studies in the context of biology and drug discovery.

\section{Methods}

General procedure. Under argon, to an oven-dried Schlenk tube $(10 \mathrm{~mL})$ equipped with a stir bar, was added NHPI redox active ester $(0.2 \mathrm{mmol}, 1$ equiv.), Eosin $\mathrm{Y}-\mathrm{Na}_{2}$ (6.8 mg, $0.01 \mathrm{mmol}, 0.05$ equiv.), and $\mathrm{HE}$ (101.2 $\mathrm{mg}, 0.4 \mathrm{mmol}, 2$ equiv.), followed by the addition of dry $\mathrm{MeCN}(2 \mathrm{~mL})$ and VSF ( $32 \mu \mathrm{L}, 0.4 \mathrm{mmol}, 2$ equiv.). The reaction mixture was then degassed by three freeze-pump-thaw cycles. The Schlenk tube was then backfilled with argon. The reaction mixture was stirred at room temperature for $12-24 \mathrm{~h}$ under the irradiation of blue LED bulb $(18 \mathrm{~W} \times 2$, at approximately $2 \mathrm{~cm}$ away from the light sources, ca. $25^{\circ} \mathrm{C}$ ). The product was purified by flash chromatography $\left(\mathrm{SiO}_{2}\right.$, petroleum ether/ethyl acetate $=20: 1$ to $4: 1$ ) to give the corresponding pure product. Full experimental details and characterization of new compounds can be found in the Supplementary Methods and Supplementary Figs. 9-108.

\section{Data availability}

The authors declare that all data supporting the findings of this study are available within the article and Supplementary Information files, and are also available from the corresponding author upon reasonable request.

Received: 27 June 2019 Accepted: 6 August 2019 Published online: 21 August 2019

\section{References}

1. Kolb, H. C., Finn, M. G. \& Sharpless, K. B. Click chemistry: diverse chemical function from a few good reactions. Angew. Chem. Int. Ed. 40, 2004-2021 (2001).

2. Dong, J., Krasnova, L., Finn, M. G. \& Sharpless, K. B. Sulfur(VI) fluoride exchange (SuFEx): another good reaction for click chemistry. Angew. Chem. Int. Ed. 53, 9430-9448 (2014)

3. Li, S., Wu, P., Moses, J. E. \& Sharpless, K. B. Multidimensional SuFEx click chemistry: sequential sulfur(VI) fluoride exchange connections of diverse modules launched from an $\mathrm{SOF}_{4}$ hub. Angew. Chem. Int. Ed. 56, 2903-2908 (2017).

4. Gao, B., Li, S., Wu, P., Moses, J. E. \& Sharpless, K. B. SuFEx chemistry of thionyl tetrafluoride $\left(\mathrm{SOF}_{4}\right)$ with organolithium nucleophiles: synthesis of sulfonimidoyl fluorides, sulfoximines, sulfonimidamides, and sulfonimidates. Angew. Chem. Int. Ed. 57, 1939-1943 (2018).

5. Guo, T. et al. A new portal to sufex click chemistry: a stable fluorosulfuryl imidazolium salt emerging as an " $\mathrm{F}-\mathrm{SO}_{2}+$ " donor of unprecedented reactivity, selectivity, and scope. Angew. Chem. Int. Ed. 57, 2605-2610 (2018).

6. Chinthakindi, P.K. \& Arvindsson, P. I. Sulfonyl fluorides (SFs): more than click reagents?. Eur. J. Org. Chem. 27-28, 3648-3666 (2018).

7. Zha, G. F. et al. $\mathrm{SO}_{2} \mathrm{~F}_{2}$-mediated oxidative dehydrogenation and dehydration of alcohols to alkynes. J. Am. Chem. Soc. 140, 17666-17673 (2018).

8. Hmissa, T. et al. Autocatalytic synthesis of bifluoride ionic liquids by SuFEx click chemistry. Angew. Chem. Int. Ed. 57, 16005-16009 (2018).

9. Gao, B. et al. Bifluoride-catalysed sulfur(VI) fluoride exchange reaction for the synthesis of polysulfates and polysulfonates. Nat. Chem. 9, 1083-1088 (2017)

10. Yang, C., Flynn, J. P. \& Niu, J. Facile synthesis of sequence-regulated synthetic polymers using orthogonal sufex and CuAAC click reactions. Angew. Chem. Int. Ed. 57, 16194-16199 (2018).

11. Brooks, K. et al. SuFEx postpolymerization modification kinetics and reactivity in polymer brushes. Macromolecules 51, 297-305 (2018).

12. Narayanan, A. \& Jones, L. H. Sulfonyl fluorides as privileged warheads in chemical biology. Chem. Sci. 6, 2650-2659 (2015).

13. Jones, L. H. Emerging utility of fluorosulfate chemical probes. ACS Med. Chem. Lett. 9, 584-586 (2018)

14. Martín-Gago, P. \& Olsen, C. A. Arylfluorosulfate-based electrophiles for covalent protein labeling: a new addition to the arsenal. Angew. Chem. Int. Ed. 58, 957-966 (2019).

15. Chen, W. et al. Arylfluorosulfates inactivate intracellular lipid binding protein (s) through chemoselective SuFEx reaction with a binding site tyr residue. $J$. Am. Chem. Soc. 138, 7353-7364 (2016).

16. Zhao, Q. et al. Broad-spectrum kinase profiling in live cells with lysinetargeted sulfonyl fluoride probes. J. Am. Chem. Soc. 139, 680-685 (2017).

17. Wang, N. et al. Genetically encoding fluorosulfate-L-tyrosine to react with lysine, histidine, and tyrosine via SuFEx in proteins in vivo. J. Am. Chem. Soc. 140, 4995-4999 (2018).

18. Uematsu, S., Tabuchi, Y., Ito, Y. \& Taki, M. Combinatorially screened peptide as targeted covalent binder: alteration of bait-conjugated peptide to reactive modifier. Bioconjugate Chem. 29, 1866-1871 (2018).

19. Liu, Z. et al. SuFEx click chemistry enabled late-stage drug functionalization. J. Am. Chem. Soc. 140, 2919-2925 (2018).

20. Yang, X. et al. An affinity-based probe for the human adenosine $\mathrm{A}_{2 \mathrm{~A}}$ receptor J. Med. Chem. 61, 7892-7901 (2018). 
21. Mortenson, D. E. et al. "Inverse drug discovery" strategy to identify proteins that are targeted by latent electrophiles as exemplified by aryl fluorosulfates. $J$. Am. Chem. Soc. 140, 200-210 (2018).

22. Brouwer, A. J. et al. Peptido sulfonyl fluorides as new powerful proteasome inhibitors. J. Med. Chem. 55, 10995-11003 (2012).

23. Dubiella, C. et al. Selective inhibition of the immunoproteasome by ligand-induced crosslinking of the active site. Angew. Chem. Int. Ed. 53, 11969-11973 (2014).

24. Fadeyi, O. O. et al. Covalent enzyme inhibition through fluorosulfate modification of a noncatalytic serine residue. ACS Chem. Biol. 12, 2015-2020 (2017).

25. Guardiola, S. et al. Targeted covalent inhibition of prolyl oligopeptidase (POP): discovery of sulfonylfluoride peptidomimetics. Cell Chem. Biol. 25, 1031-1037 (2018).

26. Artschwager, R., Ward, D. J., Gannon, S., Brouwer, A. J., van de Langemheen, H., Kowalski, H. \& Liskamp, R. M. J. Potent and highly selective inhibitors of the proteasome trypsin-like site by incorporation of basic side chain containing amino acid derived sulfonyl fluorides. J. Med. Chem. 61, 5395-5411 (2018).

27. Gooßen, L. J., Rodríguez, N. \& Gooßen, K. Carboxylic acids as substrates in homogeneous catalysis. Angew. Chem. Int. Ed. 47, 3100-3120 (2008).

28. Xuan, J., Zhang, Z. G. \& Xiao, W. J. Visible-light-induced decarboxylative functionalization of carboxylic acids and their derivatives. Angew. Chem. Int. Ed. 54, 15632-1564 (2015).

29. Wei, Y., Hu, P., Zhang, M. \& Su, W. Metal-catalyzed decarboxylative C-H functionalization. Chem. Rev. 117, 8864-8907 (2017).

30. Schwarz, J. \& König, B. Decarboxylative reactions with and without light-a comparison. Green. Chem. 20, 323-361 (2018).

31. Schwarz, J. \& König, B. Metal-free, visible-light-mediated, decarboxylative alkylation of biomass-derived compounds. Green. Chem. 18, 4743-4749 (2016).

32. Cheng, W. M., Shang, R. \& Fu, Y. Photoredox/Brønsted acid Co-catalysis enabling decarboxylative coupling of amino acid and peptide redox-active esters with N-heteroarenes. ACS Catal. 7, 907-911 (2017).

33. Candish, L., Teders, M. \& Glorius, F. Transition-metal-free, visible-lightenabled decarboxylative borylation of aryl N-hydroxyphthalimide esters. J. Am. Chem. Soc. 139, 7440-7443 (2017).

34. Fawcett, A. et al. Photoinduced decarboxylative borylation of carboxylic acids. Science 357, 283-286 (2017).

35. Zhao, W., Wurz, R. P., Peters, J. C. \& Fu, G. C. Photoinduced, copper-catalyzed decarboxylative $\mathrm{C}-\mathrm{N}$ coupling to generate protected amines: an alternative to the curtius rearrangement. J. Am. Chem. Soc. 139, 12153-12156 (2017)

36. Mao, R., Frey, A., Balon, J., Hu, X. \& Decarboxylative, C. $\left(\mathrm{sp}^{3}\right)-\mathrm{N}$ cross coupling via synergetic photoredox and Copper catalysis. Nat. Catal. 1, 120-126 (2018).

37. Wang, C. et al. Visible-light-driven, copper-catalyzed decarboxylative $\mathrm{C}\left(\mathrm{sp}^{3}\right)$ $\mathrm{H}$ alkylation of glycine and peptides. Angew. Chem. Int. Ed. 57, 15841-15846 (2018).

38. Cheng, W.-M., Shang, R. \& Fu, Y. Irradiation- induced palladium-catalyzed decarboxylative desaturation enabled by a dual ligand system. Nat. Commun. 9, 1-9 (2018).

39. Patra, T., Mukherjee, S., Ma, J., Strieth-Kalthoff, F. \& Glorius, F. Visible-light photosensitized aryl and alkyl decarboxylative functionalization reactions. Angew. Chem. Int. Ed. 58, 10514-10520 (2019).

40. Fu, M.-C., Shang, R., Zhao, B., Wang, B. \& Fu, Y. Photocatalytic decarboxylative alkylations mediated by triphenylphosphine and sodium iodide. Science 363, 1429-1434 (2019).

41. Wang, D., Zhu, N., Chen, P., Lin, Z. \& Liu, G. Enantioselective decarboxylative cyanation employing cooperative photoredox catalysis and Copper catalysis. J. Am. Chem. Soc. 139, 15632-15635 (2017).

42. Proctor, R. S. J., Davis, H. J. \& Phipps, R. J. Catalytic enantioselective Miniscitype addition to heteroarenes. Science 360, 419-422 (2018).

43. Ma, J. et al. Synthesis of $\beta$-substituted $\gamma$-aminobutyric acid derivatives through enantioselective photoredox catalysis. Angew. Chem. Int. Ed. 57, 11193-11197 (2018).

44. Qin, T. et al. A general alkyl-alkyl cross-coupling enabled by redox-active esters and alkylzinc reagents. Science 352, 801-805 (2016).

45. Lu, X., Xiao, B., Liu, L. \& Fu, Y. Formation of C(sp3)-C(sp3) bonds through nickel-catalyzed decarboxylative olefin hydroalkylation reactions. Chem. Eur. J. 22, 11161-11164 (2016).

46. Huihui, K. M. M. et al. Decarboxylative cross-electrophile coupling of N-hydroxyphthalimide esters with aryl iodides. J. Am. Chem. Soc. 138, 5016-5019 (2016).

47. Xue, W. \& Oestreich, M. Copper-catalyzed decarboxylative radical silylation of redox-active aliphatic carboxylic acid derivatives. Angew. Chem. Int. Ed. 56, 11649-11652 (2017).

48. Liu, X. G. et al. Decarboxylative Negishi coupling of redox-active aliphatic esters by cobalt catalysis. Angew. Chem. Int. Ed. 57, 13096-13100 (2018).

49. Krutak, J. J., Burpitt, R. D., Moore, W. H. \& Hyatt, J. A. Chemistry of ethenesulfonyl fluoride. fluorosulfonylethylation of organic compounds. J. Org. Chem. 44, 3847-3858 (1979).
50. Ungureanu, A., Levens, A., Candish, L. \& Lupton, D. W. N-heterocyclic carbene catalyzed synthesis of $\delta$-sultones via $\alpha, \beta$-unsaturated sulfonyl azolium intermediates. Angew. Chem. Int. Ed. 54, 11780-11784 (2015).

51. Chen, Q., Mayer, P. \& Mayr, H. Ethenesulfonyl fluoride: the most perfect Michael acceptor ever found? Angew. Chem. Int. Ed. 55, 12664-12667 (2016)

52. Qin, H. L., Zheng, Q., Bare, G. A. L., Wu, P. \& Sharpless, K. B. A HeckMatsuda process for the synthesis of $\beta$-arylethenesulfonyl fluorides: selectively addressable Bis-electrophiles for SuFEx click chemistry. Angew. Chem. Int. Ed. 55, 14155-14158 (2016).

53. Zha, G. F. et al. Palladium catalyzed fluorosulfonylvinylation of organic iodides. Angew. Chem. Int. Ed. 56, 4849-4852 (2017).

54. Chen, X.-Y., Wu, Y., Zhou, J., Wang, P. \& Yu, J.-Q. Synthesis of $\beta$ arylethenesulfonyl fluoride via Pd-catalyzed nondirected $\mathrm{C}-\mathrm{H}$ alkenylation. Org. Lett. 21, 1426-1429 (2019).

55. Hari, D. P., Schroll, P. \& König, B. Metal-free, visible-light-mediated direct C$\mathrm{H}$ arylation of heteroarenes with aryl diazonium salts. J. Am. Chem. Soc. 134, 2958-2961 (2012)

56. Fujigaya, T. et al. New photoresist materials for $157-n m$ lithography. poly [vinylsulfonyl fluoride-co-4-(1,1,1,3,3,3-hexafluoro-2-hydroxypropyl)styrene] partially protected with tert-butoxycarbonyl. Chem. Mater. 15, 1512-1517 (2003).

57. Scott, K. A. \& Njardarson, J. T. Analysis of US FDA-approved drugs containing sulfur atoms. Top. Curr. Chem. 376, 1-34 (2018).

58. Debnath, S. \& Mondal, S. Sultams: recent syntheses and applications. Eur. J. Org. Chem. 2018, 933-956 (2018).

59. Zhersh, S. A. et al. Saturated heterocyclic aminosulfonyl fluorides: new scaffolds for protecting-group-free synthesis of sulfonamides. Chem. Eur. J. 24, 8343-8349 (2018)

60. Gaulton, A. et al. ChEMBL: a large-scale bioactivity database for drug discovery. Nucleic Acids Res. 40, D1100-D1107 (2012).

61. Aminov, R. History of antimicrobial drug discovery: major classes and health impact. Biochem. Pharm. 133, 4-19 (2017).

\section{Acknowledgements}

We gratefully acknowledge the Recruitment Program of Global Experts (1000plan), Natural Science Foundation of China (Nr. 21602028), and Fuzhou University for the financial support.

\section{Author contributions}

R.X. developed the reactions, and performed the reaction scope investigation, mechanistic study, and product derivatization. T.X. and T.C. participated in the synthesis of substrates, M.Y. helped the study of the reaction scope. S.L. conceived this concept and prepared this manuscript with feedback from R.X.

\section{Additional information}

Supplementary Information accompanies this paper at https://doi.org/10.1038/s41467 019-11805-6.

Competing interests: The authors declare no competing interests.

Reprints and permission information is available online at http://npg.nature.com/ reprintsandpermissions/

Peer review information: Nature Communications thanks Zhen-Yu Tang and other anonymous reviewer(s) for their contribution to the peer review of this work. Peer reviewer reports are available.

Publisher's note: Springer Nature remains neutral with regard to jurisdictional claims in published maps and institutional affiliations.

Open Access This article is licensed under a Creative Commons Attribution 4.0 International License, which permits use, sharing, adaptation, distribution and reproduction in any medium or format, as long as you give appropriate credit to the original author(s) and the source, provide a link to the Creative Commons license, and indicate if changes were made. The images or other third party material in this article are included in the article's Creative Commons license, unless indicated otherwise in a credit line to the material. If material is not included in the article's Creative Commons license and your intended use is not permitted by statutory regulation or exceeds the permitted use, you will need to obtain permission directly from the copyright holder. To view a copy of this license, visit http://creativecommons.org/ licenses/by/4.0\%

(C) The Author(s) 2019 